\title{
Criopreservação de gametas - uma esperança para pacientes com câncer
}

Cryopreservation of gametes - a hope for cancer patients

Alessandro Schuffner ${ }^{a, b}$, Leandro Ramos ${ }^{c}$, Sandra Stockler ${ }^{a}$, Rosana Hernandes ${ }^{a}$, Sérgio Costa $^{a}$, Lidio Centa ${ }^{a, b}$

\section{Resumo}

Relatam-se dois casos de gestação bem sucedida após o sêmen ser estocado antes da quimioterapia em pacientes com câncer. No primeiro caso, o paciente teve 0 sêmen congelado aos 20 anos de idade, ao ser diagnosticado câncer de testículo; 12 anos depois, foi descongelado eusado para fertilização in vitro/injeção intracitoplasmática deespermatozóide (FIV/ICSI), resultando em gravidez única, com nascimento a termo, sem complicações no pré-natal. N o segundo caso, o paciente teve seu sêmen congelado aos 33 anos, antes da rádio-/quimioterapia para tumor neuro-ectodérmico primitivo do couro cabeludo. Estes casos dão sustentação à estocagem de sêmen, mesmo por um longo período, para homens cujo futuro de sua fertilidade possa ser comprometido através da supressão da espermatogênese secundária à administração de rádio e quimioterapia. 0 advento da ICSI veio aumentar a possibilidade de o sêmen criopreservado permitir uma gravidez, especialmente em pacientes com pequena quantidade de espermatozóides congelados. 0 armazenamento de um único ejaculado prévio ao início do tratamento com rádio-/quimioterapia pode preservar a fertilidade sem comprometimento do tratamento oncológico. $\mathrm{N}$ ão podemos esquecer também de recentes sucessos na criopreservação de tecido ovariano na abordagem das jovens com câncer.

Palavras-chave: neoplasias; criopreservação; fertilidade; fertilização in vitro; gametas.

\begin{abstract}
Two cases of successful pregnancy following semen banking before chemotherapy in cancer patients are described. In the first case, a 20 year-old patient had his semen cryopreserved after testicular cancer was diagnosed; 12 years later semen thawing was performed and used in in vitro fertilization/intracytoplasmic sperm injection (IVF/ICSI), resulting in a singleton pregnancy, uneventful prenatal with a term delivery. The second case, a 33 year-old patient had his semen cryopreserved before chemo-/radiotherapy for peripheral neuro-ectodermal tumor. These cases give support for semen banking, even for long period of time, especially men whose fertility in the future could be compromised by spermatogenesis suppression secondary to chemo- and radiotherapy administration. U sing ICSI, a cryopreserved semen has a higher chance to cause pregnancy, especially in patients with little vital sperm. Cryopreserving of a single ejaculate previous to radio/chemotherapy could preserve fertility without compromising the oncological therapy. We can not forget recent successful achievements in the cryopreservation of ovarian tissue in cancer management of young females.
\end{abstract}

Key words neoplasms; cryopreservation; fertility; in vitro fertilization; gametes.

Androlab - Clínica e Laboratório de Reprodução H umana e Andrologia, Curitiba - PR

'Serviço de Reprodução Humana do D epartamento de Tocoginecologia da Universidade Federal do Paraná (UFPR)

cH ospital Luxemburgo, Belo H orizonte - M G

Endereço para correspondência: Alessandro Schuffner - Androlab - Clínica e Laboratório de Reprodução H umana e Andrologia - Rua Bom Jesus,

758 - Curitiba - PR - 80035-010. E-mail: schuffner@androlab.com.br 


\section{INTRODUÇÃO}

0 número de pacientes que sobrevivem após o tratamento de câncer vem aumentando nos últimos anos. ${ }^{1} \mathrm{~A}$ melhoria na abordagem de jovens homens com câncer em anos recentes e um melhor entendimento dos efeitos gonadotóxicos dos agentes antineoplásicos têm motivado pacientes e médicos a preservarem a fertilidade antes de se iniciar uma terapia adjuvante. M uitos desses pacientes não completaram sua família ou ainda não a iniciaram. Estes fatores, combinados com a criopreservação de sêmen e com novas abordagens para o tratamento da infertilidade masculina, especialmente a injeção intracitoplasmática de espermatozóide, ${ }^{2,3}$ permitem a esses pacientes a possiblidade de serem pais de filhos geneticamente relacionados.

U tilizando injeção intracitoplasmática de esperma (ICSI do inglês intracytoplasmic sperm injection), são necessários poucos espermatozóides vivos após a congelamento e descongelamento para se fertilizar os oócitos. D esta forma, diferentemente do passado, não há um critério mínimo requerido para se congelar sêmen hoje em dia, uma vez que as novas técnicas reprodutivas requerem apenas alguns gametas masculinos para se obter sucesso na fertilização.

Todos os esforços devem ser concentrados no diagnóstico precoce, no sentido de curar a doença. 0 fato de que muitos cânceres, especialmente em homens jovens, são curáveis, ordena que o médico habilidoso lide não somente com o correto e precoce diagnóstico e tratamento, mas também com as necessidades do paciente após o tratamento, quando ele estiver curado.

A atuação do oncologista em conjunto com especialistas em infertilidade irá oferecer a melhor solução para estes pacientes. No sentido de preservar a fertilidade, todo esforço deve ser feito para encaminhar pacientes para que façam a criopreservação de amostras do sêmen antes do início da quimio e/ou radioterapia.

\section{RELATO DE CASO}

\section{CASO 1}

Um jovem de 20 anos de idade se apresentou em 1990 com câncer de testículo que apresentava 2 componentes, $60 \%$ carcinoma embrionário e $40 \%$ teratoma maduro/imaturo, sendo realizada orquiectomia inguinal esquerda. Seis meses depois, uma metástase pulmonar foi detectada e quimioterapia (carboplatina, ciclofosfamida e etoposide) foi prescrita. Seu sêmen foi criopreservado antes da quimioterapia no Idant Laboratories ( $\mathrm{N}$ ew York, EUA), demonstrando uma análise seminal básica pré-congelamento adequada (concentração $40 \times 106 / \mathrm{ml}$, motilidade progressiva $40 \%$ e morfologia normal 30\%). 0 sêmen foi congelado usando-se glicerol como crioprotetor, e assim mantido por 12 anos. U ma análise seminal foi realizada antes que sua esposa fosse submetida à estimulação ovariana e mostrou azoospermia completa após centrifugação em alta velocidade.

Sua esposa, de 32 anos, foi estimulada com uma combinação de agonista do hormônio liberador de gonadotrofina (aGnRH), gonadotrofinas ( $r F S H)$ e gonadotrofina coriônica humana, sendo a seguir realizadas aspiração folicular transvaginal e cultura embrionária ,como previamente publicado. ${ }^{4,5}$

A pós descongelamento do sêmen, os espermatozóides com alta motilidade foram isolados através da separação por gradiente descontínuo e depois lavados com fluido tubário humano (HTF, Irvine Scientific, Santa Ana, EU A) suplementado com proteína. A ICSI foi realizada apenas em oócitos em metáfase II.6 D ois embriões foram transferidos, usando cateter macio, através do colo uterino no terceiro dia após a aspiração oocitária guiada por ultra-sonografia transabdominal. U ma gravidez única se desenvolveu e um bebê do sexo feminino nasceu (peso de $3480 \mathrm{~g}$ e altura de $50 \mathrm{~cm}$ ) após cesariana com 39 semanas de gestação.

\section{CASO 2}

Um paciente com 33 anos foi encaminhado para esta unidade antes de iniciar quimioterapia (regime baseado em vincristina, ciclofosfamida, adriamicina, ifosfamida e etoposide) e radioterapia (2.100 cGy, divididos em 26 seções) por apresentar tumor neuroectodérmico primitivo em couro cabeludo. Seu sêmen foi criopreservado na Androlab (C uritiba, Brasil), demonstrando uma adequada análise seminal básica précongelamento (concentração 278x106/ml, motilidade progressiva 30\%). 0 sêmen foi congelado usando um tampão com gema de ovo (TEST Yolk Buffer, Irvine Scientific, EU A) como crioprotetor emantido congelado por 16 meses.

Sua esposa, com 32 anos, teve sua estimulação ovariana realizada com uma combinação de agonista do hormônio liberador de gonadotrofinas (aGnRH), gonadotrofinas ( $\mathrm{rFSH}$ ) e gonadotrofina coriônica humana. Um total de 18 oócitos em metáfase II foram aspirados e submetidos à IC SI, sendo formados 15 embriões. Três embriões foram transferidos três dias após a aspiração oocitária guiada por ecografia transabdominal usando catéter macio. Os doze embriões restantes foram criopreservados. U ma gravidez única se desenvolveu e um bebê do sexo feminino nasceu (peso 
de $2750 \mathrm{~g}$ e altura de $48 \mathrm{~cm}$ ) após cesariana com 39 semanas de gestação.

\section{DISCUSSÃO}

Estes relatos demonstram que a criopreservação de sêmen permite ao homem portador de neoplasia se tornar pai, até mesmo se submetido a tratamentos agressivos, como orquiectomia, quimioterapia e radioterapia, ainda que os espermatozóides permaneçam congelados por longo período. Todo esforço deve ser feito para encaminhar pacientes com câncer para a criopreservação de sêmen antes de se iniciar a quimio e radioterapia.

A criopreservação do sêmen antes do início de um tratamento que provoque esterilidade permite o emprego de técnicas de reprodução assistida, especialmente a micromanipulação de gametas, bastando que uma amostra com pequeno número de espermatozóides esteja disponível.

U ma preocupação no manejo dos pacientes com câncer é que até $90 \%$ deles terão azoospermia poucas semanas após o início da quimioterapia, e apenas 20 $50 \%$ reassumem a espermatogênese dois a três anos após término do tratamento. ${ }^{7}$

O utro importante aspecto é a necessidade do congelamento de oócitos/tecido ovariano em mulheres jovens que se apresentam com câncer, oferecendo a possibilidade de elas terem sua fertilidade restaurada após terapias esterilizantes. ${ }^{8}$ Algum sucesso tem sido relatado usando-se esta técnica. ${ }^{9,10} 0$ entendimento da criopreservação de oócitos e tecido ovariano é desejável para se oferecer essa tecnologia também a pacientes com risco maior de falência ovariana prematura. ${ }^{11}$ Existe uma preocupação legítima no que diz respeito ao risco potencial de se reintroduzir células malignas com 0 transplante ovariano, dependendo do tipo de câncer. N o entanto, há um interesse grande no desenvolvimento de técnicas de maturação in vitro de oócitos, para que não haja necessidade de se transplantar o tecido ovariano para o organismo da mulher para esse fim.

Sendo assim, com os recentes desenvolvimentos nas tecnologias de reprodução assistida, as pacientes com câncer devem ser encorajadas a preservarem seu potencial reprodutivo. Atualmente, um ou dois ciclos de fertilização in vitro pré-tratamento com a criopreservação de embriões é a melhor opção. A criopreservação de tecido ovariano, oócitos imaturos ou maduros é uma técnicas em desenvolvimento e pode ser considerada para algumas pacientes. Se a falência gonadal é um resultado provável, as esperanças recaem sobre as intensas evoluções na estocagem de tecido ovariano. Em vista disso, o desenvolvimento dessa nova tecnologia é muito desejável pela sua alta aplicabilidade em pacientes jovens que venham a ser submetidas, com sucesso, a tratamentos agressivos contra as mais diversas neoplasias.

0 ressurgimento da indicação de criopreservação ovariana se deve à melhoria da taxa de sobrevivência a longo prazo em pessoas jovens, portadoras de doenças malignas, as quais são submetidas a tratamentos agressivos com terapias oncológicas modernas, incluindo quimioterapia e radioterapia. Como resultado, um grande número de pacientes jovens têm sido curadas de suas neoplasias, mas permanecem com a falência ovariana ${ }^{12}$.

Segundo Schuffner et al. ${ }^{13}$, é importante salientar que mesmo com sêmen criopreservado por longo período é possível conseguir-se uma gravidez viável. É importante oferecer aos pacientes que serão submetidos à quimio e/ ou radioterapia esta possibilidade, embora eles possam não estar pensando em se tornar pais naquele momento. A criopreservação de sêmen deve ser, portanto, parte de uma rotina no manejo terapêutico para preservar a fertilidade em homens jovens com doenças neoplásicas.

\section{REFERÊNCIAS BIBLIOGRÁFICAS}

1. Byrne J, M ulvihill JJ, M yers M H, C onnelly RR, N aughton $M D, K$ rauss $M R$, et al. Effects of treatment on fertility in long-term survivors of childhood or adolescent cancer. N Engl J M ed 1987;317:1315-21.

2. Palermo G, Joris H, D evroey P, Van Steirteghem AC. Pregnancies after intracytoplasmic sperm injection of a single sperm into an oocyte. Lancet 1992;340:17-8.

3. Schuffner $A, M$ onzo $A$, Centa $L J R$, M orshedi $M$, 0 ehninger $S$. Resultado de ICSI em pacientes azoospérmicos. J Bras Reprod Assist 2001;5:106-10.

4. Schuffner A, Spautz C, C ostaS, Pereira A, Júlio H, Centa L. G estação tubária após transferência embrionária ultrauterina homolateral à ectópica prévia pós-concepção natural tratada com doseúnica demetotrexate. Rev M éd Paraná 2003;61:30-3.

5. Schuffner A, Wonsttret L, M oraes R, Stockler S, Trovão A, CostaS, et al. A eficiência do programa dedoação deóvulo em pacientes com reserva ovariana diminuída. Rev M éd Paraná. In press 2003.

6. Schuffner A, Stockler S, PereraA, CostaS, CentaL. Gravidez enascimento resultante detransferência deembrião com um pró-núcleo apósfalhasconsecutivas deFIV. Rep Clim. In press 2004.

7. Kreuser ED, H arsch U, H etzel D, Schreml W. Chronic gonadal toxicity in patientswith testicular cancer after chemotherapy. Eur J Cancer Clin O ncol 1986;232:289-94.

8. Schuffner A, Piazza M, CostaS, CentaL. Criopreservação 
detecido ovariano: revisão histórica. Femina2003;31:63-6.

9. O ktay K, Aydin BA, Karlikaya G. A technique for laparoscopic transplantation of frozen-banked ovarian tissue. Fertil Steril 2001;75:1212-6.

10. RadfordJA, Lieberman BA, Brison D R, Smith AR, Critchlow JD , Russell SA, etal. O rthotopicreimplantation of cryopreserved ovarian cortical strips after high-dose chemotherapy for H odgkin'slymphoma. Lancet 2001; 357:1172-5.

11. Picton H M , Gosden RG , Leibo SP. G amete source, ma- nipulation and disposition. In: Vayena E, editor. Current practicesand controversiesin assisted reproduction. G eneva: World $\mathrm{H}$ ealth $\mathrm{O}$ rganization; 2002. p. 142-51.

12. ChambersSK, ChambersJT, Kier R, Peschel RE. Sequelae of lateral ovarian transposition in irradiated cervical cancer patients. IntJ Radiat O ncol Biol Phys 1991;20:1305-8.

13. Schuffner A, Stockler S, Costa S, Centa L. Long-term cryopreserved semen resultsin a livebirth twelveyearslater. J U rol 2004;171:358. 